\title{
Graves hyperthyroidism in pregnancy: a rare presentation
}

\author{
Priyanka Garg, Romi Bansal, Roushali*
}

Department of Obstetrics and Gynecology, Adesh Institute of Medical Sciences and Research, Bathinda, Punjab, India

Received: 12 August 2019

Accepted: 05 September 2019

\section{*Correspondence:}

Dr. Roushali,

E-mail: rushalikumar0093@gmail

Copyright: ( ) the author(s), publisher and licensee Medip Academy. This is an open-access article distributed under the terms of the Creative Commons Attribution Non-Commercial License, which permits unrestricted non-commercial use, distribution, and reproduction in any medium, provided the original work is properly cited.

\begin{abstract}
Hyperthyroidism in pregnancy is much less common occurring in $0.1-0.2 \%$ of women with Grave's disease being the most common cause accounting for $90 \%$ of the cases. It is important to diagnose hyperthyroidism in pregnancy because fetal loss in untreated patients is high and may even be life threatening for the mother. We are presenting a case of 29 years old G3P2L1 who presented to our emergency with amenorrhea of 7 months and history of loose stools for the last 20 days. It was associated with generalized weakness. She also had history of palpitations, weight loss and sleep disturbances. She was a known case of hyperthyroidism for the past 1-2 years and was already taking anti-thyroid drugs. B/L exophthalmos was apparently present. Patient was severly anaemic with haemoglobin of $5.5 \mathrm{gms} / \mathrm{dl}$. Ultrasound showed fetal demise at 28 weeks. Patient was given 3 units of blood transfusion and was induced with prostaglandins. She delivered a dead male baby weighing $1.2 \mathrm{kgs}$. Her postpartum period was uneventful. Timely diagnosis of graves hyperthyroidism and its optimal treatment throughout pregnancy is vital in reducing maternal, fetal and neonatal complications.
\end{abstract}

Keywords: Anti-thyroid drugs, Exophthalmos, Grave's disease, Hyperthyroidism, Thyroidectomy

\section{INTRODUCTION}

Hyperthyroidism in pregnancy is much less commonly occuring in 0.1 to $0.2 \%$ of women with graves' disease being the most common cause accounting for $90 \%$ of the cases. ${ }^{1,2}$ Graves's hyperthyroidism is an autoimmune condition caused by the production of auto-antibodies directed against thyroid stimulating hormone receptor. It is important to diagnose hyperthyroidism in pregnancy because fetal loss in untreated patient is high $(5.6 \%)$ and may even be life threatening for the mother. ${ }^{3}$

\section{RESULTS}

A 29 years old G3P2L1 with gestational age 29 weeks 6 days came to Department of Obstetrics and Gynecology at Adesh Medical College, Bathinda with chief complaints of increased frequency of loose stools since 20 days. It was associated with pain lower abdomen and fever. She was an unbooked case. She was known case of hyperthyroidism for past 2 years with all the typical clinical features such as palpitation, tremors, weight loss, insomnia, hair loss, muscle weakness and obvious bilateral exophthalmos. Patient was already taking tablet neomercazole $10 \mathrm{mg}$ BD. Her obstetric history revealed previous full term intrauterine death 2 years back with no known cause.

- On physical examination- Patient was lean

- Pulse rate- 110 beats/min

- Blood pressure- $100 / 60 \mathrm{mmHg}$

- Pallor- +++

- Febrile to touch

- Her BMI- 18.38 (weight 50kg, height- 165cm) 
- Bilateral exophthalmos was apparently present

- Chest auscultation-bilateral normal vesicular breathing. No added sounds

- Per abdomen- uterus 26-28 weeks, relaxed, Fetal heart sound not localised

- Investigation

- $\mathrm{Hb}-5.5 \mathrm{gm}$

- PBF- dimorphic anaemia

- $\quad$ TLC- 16000

- LFT- WNL

- $\quad$ RFT- WNL
- S.electrolytes- WNL

- S.TSH- 0.02

- $\quad$ FT4- 17.3

- Thyrotropin receptor antibodies- positive

- $\quad$ PT/INR- 1.36

USG revealed single intrauterine pregnancy with no cardiac activity at 28 weeks.

Patient was given 3 units of packed red blood cell and induced with prostaglandin. She delivered dead male baby weighing $1.2 \mathrm{~kg}$. Her postpartum period was uneventful.

Table 1: Trimester- specific ranges for thyroid tests. ${ }^{9,10}$

\begin{tabular}{|lllll|}
\hline Test & Non pregnant & First trimester & Second trimester & Third trimester \\
\hline TSH (mIUperL) & $0.3-4.3$ & $0.1-2.5$ & $0.2-3.0$ & $0.3-3.0$ \\
\hline TBG (mgperdl) & $1.3-3.0$ & $1.8-3.2$ & $2.8-4.0$ & $2.6-4.2$ \\
\hline FT4 (ngperdl) & $0.8-1.7$ & $0.8-1.2$ & $2.8-4.0$ & $2.6-4.2$ \\
\hline FT3 (ng per dl) & $2.4-4.2$ & $4.1-4.4$ & $4.0-4.2$ & Not reported \\
\hline Total T3 $($ ng per dl) & $77-135$ & $97-149$ & $117-169$ & $123-162$ \\
\hline
\end{tabular}

\section{DISCUSSION}

Hyperthyroidism is defined by abnormally high levels of thyroid hormone caused by increase synthesis and secretion of thyroid hormone from thyroid gland4. Uncontrolled thyrotoxicosis is associated with pregnancy loss, pregnancy induced hypertension, prematurity, low birth weight, intrauterine growth restriction, intrauterine death (as seen in our case), thyroid storm and maternal congestive heart failure. ${ }^{5-7}$ Graves' disease is the most common cause but gestational transient hyperthyroidism may occur in $1-3 \%$ of pregnancies. ${ }^{8}$ It is important to differentiate between the graves' disease and gestational transient hyperthyroidism as the latter does not require any specific treatment. The findings of

- History of thyroid disease before pregnancy

- Stigmàta of graves' disease (goitre, orbitopathy)

- $\quad$ Present of thyrotropin receptor antibody ${ }^{9}$

Points towards diagnosis of graves' disease (as seen in our case) needs to treat with antithyroid drugs. The dose of antithyroid drugs should be lowest possible targeting maternal FT4/TT4 in upper limit or moderately above reference range to prevent fetal hypothyroidism.

The preffered drug is propylthiouracil over methimazole in the first trimester due to less severe and surgically correctable birth defects and changed to methimazole at beginning of second trimester. Monitoring is done by FT4 and TSH every 2-4 weeks and latter 4-6 weeks after achieving target level. ${ }^{11,12}$ Maternal TRAb levels if initially elevated, should be measured again at 18 to 22 weeks and 28 to 34 weeks. If anti-thyroid drugs are not tolerated, fails to achieve the euthyroid state, allergic to drug, has a large goiter and requiring very high doses of drugs, thyroidectomy in second trimester is preferably the alternative treatment. ${ }^{9}$ In the present case, patient had graves hyperthyroidism since last 2 years which was poorly controlled and her thyroid function test not monitored reguraly and she conceived without being in euthyroid state which lead to fetal loss. This uncontrolled hyperthyroidism could be the cause of her previous loss also. Such patient is at risk of developing recurrent graves' disease 4-12 months after delivery. TSH ànd FT4 should be checked routinely in the first year starting at 6 weeks after delivery.

\section{CONCLUSION}

Timely diagnosis of graves hyperthyroidism and its optimal treatment throughout pregnancy is vital in reducing maternal, fetal and neonatal complication but it is a challenging task due to various factors such as effect of pregnancy on thyroid physiology, laboratory testing and teratogenic effects of anti-thyroid drugs.

Funding: No funding sources

Conflict of interest: None declared

Ethical approval: Not required

\section{REFERENCES}

1. Cooper DS, Laurberg P. Hyperthyroidism in pregnancy. Lancet Diabetes Endocrinol. 2013;1(3):238-49.

2. De Groot L, Abalovich M, Alexander EK. Management of thyroid dysfunction during 
pregnancy and postpartum: an Endocrine Society clinical practice guideline. J Clin Endocrinol Metab. 2012;97(8):2543-65.

3. Hamburger JI. Diagnosis and management of Graves' disease in pregnancy. Thyroid. 1992;2(3):219-24.

4. Franklyun JA, Boelaert K. Thrytoxicosis. The Lancet. 2012;379(9821):1155-66.

5. Davis LE, Lucas MJ, Hankins GD, Roark ML, Cunningham FG. Thyrotoxicosis complicating pregnancy. Am J Obstet Gynecol. 1989;160(1):63-70.

6. Mestman JH. Hyperthyroidism in pregnancy. Best Pract Res Clin Endocrinol Metab. 2004;18:267-88.

7. Laurberg P, Bournaud C, Karmisholt J, Orgiazzi J. Management of Graves' hyperthyroidism in pregnancy: focus on both maternal and foetal thyroid function, and caution against surgical thyroidectomy in pregnancy. Eur J Endocrinol. 2009;160(1):1-8.

8. De Groot L, Abalovich M, Alexander EK, Amino N, Barbour L, Cobin RH, et al. Management of thyroid dysfunction during pregnancy and postpartum: an Endocrine Society clinical practice guideline. J Clin Endocrinol Metab. 2012;97(8):2543-65.
9. Stagnaro-Green A, Abalovich M, Alexander E. Guidelines of the Amercan Thyroid Association for the diagnosis and management of thyroid disease during pregnancy and postpartum. Thyroid. 2011;21(10):1081-125.

10. Abbassi-Ghanavati M, Greer LG, Cunningham FG. Pregnancy and laboratory studies: a reference table for clinicians. Obstet Gynecol. 2009;114(6):1326-31.

11. Andersen SL, Olsen J, Wu CS, Laurberg P. Severity of birth defects after propylthiouracil exposure in early pregnancy. Thyroid. 2014;24(10):1533-40.

12. Bahn RS, Burch HS, Cooper DS, Garber JR, Greenlee $\mathrm{CM}$, Klein IL, et al. The role of Propylthiouracil in the Management of Graves' disease in adults: report of a meeting jointly sponsored by the American Thyroid Association and the Food and Drug Administration. Thyroid. 2009;19(7):673-4.

Cite this article as: Garg P, Bansal R, Roushali. Graves hyperthyroidism in pregnancy: a rare presentation. Int J Reprod Contracept Obstet Gynecol 2019;8:4104-6. 